\title{
Integrating Emotions and Affect in Theories of Management
}

\author{
Neal M. Ashkanasy \\ UQ Business School \\ The University of Queensland \\ Brisbane, QLD 4072 Australia \\ e-mail:n.ashkanasy@uq.edu.au \\ Ronald H. Humphrey \\ Department of Leadership and Management \\ Lancaster University Management School \\ Lancaster University \\ Lancaster, United Kingdom LA1 4YX \\ e-mail: r.humphrey@lancaster.ac.uk \\ Quy Huy \\ INSEAD \\ 1 Ayer Rajah Avenue \\ 138676 Singapore \\ e-mail: quy.huy@insead.edu
}

Ashkanasy, N. M., Humphrey, R. H., \& Huy, Q. N. (forthcoming, April, 2017). Integrating affect and emotion in management theories. Academy of Management Review. 


\title{
Integrating Emotions and Affect in Theories of Management
}

\begin{abstract}
Scholars have studied emotions and affect in organizational settings for over twenty years, providing numerous insights into understanding how organizations and the people who work in them behave. With such a rich accumulation of knowledge, the time seemed right to call for today's scholars of management to propose new and exciting theory. The eight articles in this Special Topic Forum address topics that cross multiple levels of analysis and include a range of different theories, explicating: how anger and fear can spark productivity, how employees respond to abusive supervision over time, how leader-member exchanges are shaped by affective events, the social functions of emotional complexity for leaders, team entrepreneurial passion, the effects of institutional beliefs on emotional displays, the nexus of affective climate and organizational effectiveness, and the role of gratitude in organizations. In this introduction, we briefly summarize the main points from each article, and discuss new research directions arising from the articles. To spur even deeper research into this important and still unfolding field of discovery, and stimulated by the articles in this STF, we conclude with additional thoughts and ideas on the role of emotions and affect in organizations,.
\end{abstract}

[192 words] 


\section{Integrating Emotions and Affect in Theories of Management}

Organizations are intrinsically human entities. As such, the processes that drive human thought and behavior also drive organizations. Understanding organizations therefore requires understanding of the processes that guide human behavior and decision-making. These processes in turn emanate from the human brain, which is the source of two related but nonetheless differentiable phenomena: cognition and affect. These statements are axiomatic yet, until recently, organizational scholars tended to favor explanations of organizational behavior and decision-making that assume the human brain reacts in predictable and programmatic ways to environmental contingencies and stimuli. Just twenty years ago, for example, Ashforth and Humphrey (1995) commented that scholars up until that time seemed to have neglected the role of "everyday emotions" in studies of organizations.

The mid-1990's appears to have been the turning point, however. Weiss and Cropanzano (1996) published “Affective Events Theory," where they proposed that behavior in organizations is intrinsically driven by members' emotional reactions to events in their environment. Also, Goleman (1995) published his best-seller Emotional Intelligence: Why it can matter more than $I Q$, which served to popularize the notion that emotions played a central role in human behavior in general. Goleman (1998) followed up with a book that applied his ideas specifically to organizations. The year 1997 saw the establishment of the Listserv Emonet which serves as an international forum for scholars working in the field, followed shortly thereafter by the first International Conference on Emotions and Worklife (see http://www.emotionsnet.org). Also this period saw publication of a raft of journal special issues on the topic (e.g., see Ashkanasy, 2004; Fisher \& Ashkanasy, 2000; Fox \& Spector, 2002; Humphrey, 2002).

Post-2003, researchers continued to emphasize the centrality of affect and emotion in organizational research. In this regard, Ashkanasy (2003a) proposed a multi-level framework 
of emotion in organizations that encompasses emotions as a within-person and betweenpersons variable, as well as recognizing interpersonal, group, and organization-wide levels of analysis; and Elfenbein (2007:318) later published a "Process Framework" that focuses on emotion as an essentially interpersonal phenomenon and connects across different levels of analysis. In a more recent and comprehensive state-of-the art review, Ashkanasy and Humphrey (2011a: 220) concluded that "this is a growing and vibrant field of research, with untapped potential."

Indeed, empirical research on emotions and affect at work continues to grow. For instance, a Google Scholar search reveals that some 260,000 articles have used the terms “emotional labor" (also spelled "emotional labour") or "emotional intelligence", with more than 50,000 of these published since 2012. Emotional labor has been studied extensively among service workers, and recent research suggests that leaders and subordinates also use emotional labor in their interactions with each other, while emotional intelligence has been studied right across a diverse range of organizational settings and variables. Clearly, just these two lines of inquiry have potential for incorporation into our core theories of management. Moreover, recent theories of emotions are being applied in new ways to a wide variety of management topics, some of which had previously given little attention to affect. For example, emotions are now being studied with regard to topics like strategy (AshtonJames \& Ashkanasy, 2008; Hodgkinson \& Healey, 2011; Huy, 2011), entrepreneurship (Cardon, Wincent, Singh, \& Drnovsek, 2009; Shepherd, Wiklund, Haynie, 2009), and organizational change (Huy, 1999, 2002; Seo et al., 2012). As Cardon and her colleagues stated in their introduction to the special issue of Entrepreneurship Theory and Practice on affect, "Entrepreneurial emotion is a hot topic" (Cardon, Foo, Shepherd, \& Wiklund, 2012: 1). At the other end of the spectrum, breakthrough studies are documenting the neurological basis of affect and leadership (e.g., see Waldman, Balthazard, \& Peterson, 2011). 
In view of this "untapped potential," identified by Ashkanasy and Humphrey (2011a), it seemed that the time was ripe for us to call for organizational scholars to submit their ideas for further theoretical development in this field. The manuscripts we received cross multiple levels of analysis, ranging from micro (within temporal variability, between-persons), to meso (interpersonal relationships and teams), and then to macro (organization wide). In the following discussion, we introduce each of the articles in this STF, ordering them according to level of analysis, from micro to macro.

\section{The Articles}

In the first of the articles included in this STF, Lebel (2017) develops what he refers to as a "contingent model of how anger and fear spark productivity." Situated at micro- to meso-levels of analysis (within-person, between persons, interpersonal), Lebel's arguments constitute a significant departure from the more traditional view of negative emotion as a source of non-optimal outcomes in organizational settings, especially when it comes to productivity. This is in contrast to the literature that has sprung up around ideas of "Positive Organizational Studies" (Dutton \& Quinn, 2003) and "Positive Organizational Behavior" (Luthans, 2002). In particular, positive affect is usually linked to creativity, as encapsulated in Fredrickson's (2001) “Broaden and Build” Theory. More recent research (e.g., To, Fisher, Ashkanasy, 2015; To, Fisher, Ashkanasy, \& Rowe, 2012), however, has revealed that negative emotions can also play a positive role in promoting creativity and productivity. What has been missing to date, however, has been a cogent theoretical framework that will enable us to understand the processes underlying this seemingly paradoxical situation. This is exactly what Lebel set out to do in this article. Focusing specifically on the discrete negative emotions of anger and fear, Lebel seeks to address the issue through the lens of proactive behavior theory (Parker, Bindl, \& Strauss, 2010) with a view to identifying the conditions 
under which "anger and fear prompt proactive behavior." In a deceptively simple model, the author explains how anger (via self-efficacy) and fear (via protective effort) can lead to productive behavior under particular personal and environmental circumstances, especially when the individual possesses emotional regulation knowledge. The model, which incorporates four propositions, is compelling in its simplicity, and is sure to contribute to our understanding of how and when negative emotions can contribute to productive behavior, with implications for both research and practice.

The second of the articles in this STF is also situated at micro- to meso-levels of analysis. In it, authors Oh and Farh (2017) present an emotional process theory of how subordinates appraise, experience, and respond to abusive supervision over time. As the title of this article suggests, the authors tie in cognitive processes, namely appraisals and attributions, to emotional processes. Although often treated as separate, emotions and cognitions are intricately and inseparably linked (Lazarus \& Folkman, 1984). Furthermore, Oh and Farh examine the role of situational constraints on appraisals and emotional processes, and ultimately on the resulting reactions to abuse. In terms of appraisals, the authors classify appraisals as either primary or secondary. Primary appraisals are influenced by the novelty of the abuse and by goal congruency. Novelty influences attributions about whether the behavior is abusive or not, depending upon behavioral norms and the context. Goal congruence is influenced by the person's ego sensitivity and by whether subordinate's friends are also subject to abuse. Secondary appraisal dimensions consist of blame, certainty, and coping potential. The authors assign a key role to emotional regulation ability when explaining individual coping potential.

Because their article deals with abusive supervision, Oh and Farh (2017) focus on three discrete negative emotions that can result: fear, anger, and sadness. According to their model, fear is associated with what that they term an "emotivational goal" to escape harm; 
anger with the goal to remove harm; and sadness with the acceptance of loss. These different emotions trigger distinct behavioral responses. One of the major contributions of the article is that its authors specify seven different types of behavior responses according to the types of emotions and the behavioral pathway. For anger and sadness, these behavioral pathways are categorized into three types: dominant, constrained, and regulated. For sadness, there is no action tendency other than withdrawal and disengagement. Thus, this article greatly expands our understanding of how people respond to abusive supervision.

Attention in the third of the articles in this STF turns to the meso-level issue of leadership and focuses on the means by which leader-member exchanges are shaped by affective events (at the micro-level). Authors Cropanzano, Dasborough, and Weiss (2017) develop a model of the three stages of leader-member exchange (LMX) relationship development (role taking, role making, role routinization) using an affective events theory (AET: Weiss \& Cropanzano, 1996) lens. Thus, in the role-taking stage, leaders signal their willingness to engage in a high quality LMX with individual followers. Their display of emotions is a key signalling device, and emotional contagion and affective empathy also have a powerful effect on the quality of leader-member relationships. Although many models focus on how leaders' emotional displays influence followers, the authors of this article explicate how both followers and leaders are influenced by affective events and by each other's emotional expressions. As a result, leaders and followers may become "affectively entrained," in that their emotions fluctuate together. Moreover, because emotions are such a key part of any relationship, this common rhythm holds potential to improve the quality of the leader-member relationships. The authors realize that entrainment is not a simple process, and they model different patterns of entrainment and discuss the implications of each pattern.

Cropanzano and his colleagues (2017) are especially insightful insofar as they analyze the effects of affective entrainment at the group level. LMX theory posits that leaders have 
unique relationships with individual members of their team. Moreover, LMX holds that some of these relationships develop into high quality relationships marked by mutual liking and respect, perhaps even by close friendship. In contrast, other relationships are low quality and devoid of real interpersonal affection, so that managers use formal rules and rewards to motivate these followers. As a result, the LMX relationships become differentiated according to levels of liking and shared leader-follower emotions. Stemming from these ideas, the authors develop a series of testable propositions that examine how this relative LMX affects specific emotions. Followers who perceive that others have higher quality relationships with the leader may feel anger, disgust, and contempt towards the leader, especially if they feel that their relative status is unjust. In contrast, followers who perceive that they are in the leader's good graces and enjoy a positive relative standing vis-a-vis their teammates may experience positive emotions like gratitude. The authors conclude by discussing how these emotions either improve or degrade the quality of the LMX relationships over time.

Also on the topic of leadership within a multi-level framework, the authors of the fourth article in this STF (Rothman \& Melwani, 2017) focus on the social functions of emotional complexity for leaders. Rothman and Melwani challenge the commonly held assumption that emotional complexity - defined as the simultaneous or sequential experience of at least two different emotional states during the same emotional episode - represents a leadership weakness (i.e., conveying leader indecisiveness and fostering cognitive rigidity). The authors argue that emotional complexity represents a more developed reaction to complex change events (that often exhibit contradicting demands by various stakeholder groups) than emotional simplicity such as just feeling "positive" or "negative." Emotional complexity could help enhance leadership of change.

Drawing on functional theory of emotion, Rothman and Melwani (2017) argue that emotional complexity should facilitate the level of intra-personal cognitive flexibility that 
allows a balanced consideration of multiple divergent perspectives, thus enhancing creative adaptation during a change process. In interpersonal interactions, leaders' expressions of emotional complexity should also stimulate creative thinking in followers because it conveys leaders' role modelling and support for followers' openness and flexibility, thus fostering honest dialogue and learning from mistakes during a change process. The authors also point to important contingency conditions, such that leaders who are high on neuroticism and low in openness to experience will be less likely to become cognitively flexible. Moreover, followers who share the same vantage point with their leaders - and who perceive their leaders as dealing with competing demands - will be more likely to judge their leaders as cognitively flexible.

Beyond bringing a fresh emotion-based perspective to the change literature, the theory proposed by Rothman and Melwani (2017) should also bring an enriched perspective to the leadership literature that has often focused on leaders' relatively stable trait in terms of leader flexibility and adaptability. Rather, they propose that state emotions act as dynamic enablers of flexibility and show how these states could change from one situation to the next.

Moving on from leadership, the fifth article in this STF spans meso- to macro-levels of analysis and deals with the issue of emotions in entrepreneurship. Indeed, perhaps no topic in management evokes more emotions than the passion of entrepreneurship. As Cardon et al. (2009) pointed out, entrepreneurs are by nature passionate about what they do. But entrepreneurs seldom operate alone. They need to assemble a team of entrepreneurial peers who can push their ideas though to realization. In this STF article, authors Cardon, Post, and Forster (2017) seek to address this issue by building on the earlier individual-level theory and extending it to the team level of analysis. They do this though a concept they refer to as “Team Entrepreneurial Passion" (TEP). According to Cardon and her colleagues (2017), this 
represents "the level of shared intense positive feelings for a collective and central team identity for new venture teams (NVTs)."

As with all team-level constructs, TEP presents a set of unique challenges, not the least of which is to model the team processes that underlie the development of this phenomenon. In particular, the question arises as to how a group of entrepreneurs can combine their own entrepreneurial passions in a cohesive fashion such that the team (rather than a group of individuals) develops a sense of purpose. This is a non-trivial question, involving issues of shared affect, affective diversity, and the development of a shared collective identity. To deal with this, Cardon et al. (2017) develop a dynamic cyclical model of individual and entrepreneurial passion accompanied by a set of nine specific propositions linking between and across the two level of analysis. The resulting model provides a clear way forward for researchers seeing to explain this important, yet complex process.

Also crossing meso- to macro-levels of analysis, Jarvis (2017) deals in the sixth STF article with the effect of feigning emotions on institutional logics. As such, this essay represents one of the rare works that links micro emotional behavior to institutional theory, showing how institutional beliefs have the potential to shape emotional display behaviors, and how these behaviors in turn could contribute to maintaining or changing the institutions in which they are embedded. Challenging the often taken-for-granted assumption that authentic emotional displays are normatively desirable, Jarvis theorizes as to how feigning behaviors - or emotional displays that differ in valence or intensity from physiological experience - represent strategic behaviors that could be adaptive in regard to satisfying institutionalized norms.

Jarvis (2017) thus unpacks the dichotomous notion of authentic versus inauthentic emotional display and theorizes about the function of three types of emotional display or feigning: display that is aligned with actual physiological experience; feigning emotional 
display that exhibits the same valence but could differ in intensity; and feigning with displaying emotion that has the opposite valence of physiological experience. He then discusses various ways in which these types of emotional displays could help maintain social order or motivate change, providing illustrative evidence drawn in diverse contexts such as customer service, work identity, and social movement. In so doing, he integrates eclectic insights from the literatures in institutional logics, emotion regulation, emotional labor, emotional contagion, organizational change, organizational culture, and leadership. He then uses these insights to formulate revelatory, non-intuitive predictions about how various types of emotional feigning behaviors - varying in valence, intensity, or duration - could contribute to the maintenance of various institutional logics, blending, and at the same time supporting the contestation of the same logics.

In sum, we expect this essay to open fresh pathways for research that links emotionrelated behaviors to macro level society and institutions, and to investigate various contextual conditions and underpinning mechanisms that link these micro emotional behaviors to institution-level factors and outcomes; secondly, this work could serve as one of the rare exemplars for scholars to produce more works that link micro emotion to macro factors in insightful ways.

In the seventh of the articles in this STF, Parke and Seo (2017) develop a macro-level theory around the role of affect climate in organizational effectiveness. The concept of affective climate has been with us since its introduction by sociologist Joseph de Rivera (1992). Our understanding of the psychological nature of the construct, however, continues to be elusive. Parke and Seo endeavor in this article to build upon previous work in this field (Ashkanasy, \& Härtel, 2014; Ostroff, Kinicki, \& Muhammad, 2013; Schneider, Ehrhart, \& Macey, 2013) to outline a comprehensive model of the antecedents and effect of affect climate in organizations. In their model, company practices, leaders, and routines combine to 
contribute to the development of an affective climate that affects employees' expression and experience of emotion. This effect in turn flows on to affect employees' mood state and, ultimately their accomplishment of functional goals. Parke and Seo go on to identify six particular affect climate types and explain how these types "differentially impact four strategic outcomes of organizational units: relationship, productivity, creativity, and reliability performance." This is the first time to our knowledge that a comprehensive explanatory model of affect culture and its effects has been proposed. The model is ripe with research possibilities, especially given the importance of affect climate as a driver of employee behavior and, ultimately, of organizational success outcomes.

Finally, in the eighth article in the STF, Fehr, Fulmer, Awtrey, and Miller (2017) address a novel topic: the role of gratitude in organizations. The model is once again multilevel, crossing micro- to macro-levels of analysis. Based in the work of Emmons and McCullough (2004) Fehr and his associates define gratitude as "A feeling of appreciation in response to an experience that is beneficial to, but not attributable to, the self." They note in particular that, while gratitude is generally seen to be important to human relationships, the concept has rarely been studied with regard to organizational behavior. Fehr and his colleagues rectify this situation in their insightful article on gratitude at multiple levels. Thus, they examine episodic gratitude (which occurs at the event level), persistent gratitude (at the individual level), and collective gratitude (at the organizational level). Most research has focused on gratitude at the episodic or event level, which occurs when people interpret help or other beneficial behaviors from others in a way that promotes feelings of gratitude. The interpretation of events plays an important role, because not everyone is willing to recognize the beneficial help they receive from others.

Fehr and his coauthors (2017) define persistent gratitude "as a stable tendency to feel grateful within a particular context." They conceptualize persistent gratitude not as a trait but 
as a schema, or mental representation. Individuals with abusive managers and workplaces develop negative schemas about the workplace that do not support the development of gratitude. In contrast, employees in positive workplaces with helpful and friendly leaders and coworkers develop schemas that support persistent feelings of gratitude. Their focus on schemas creates a logical tie-in to their emphasis on context.

The emphasis on context, in turn, allows the development of a wide range of theoretically based strategies for creating organizational cultures that support collective gratitude. Fehr et al. (2017) define collective gratitude as "persistent gratitude that is shared by the members of an organization." They argue that this collective gratitude is an emergent process that results from shared interactions. Because of gratitude's importance, they argue that the amount of collective gratitude in an organization becomes a key aspect of its culture. They then go on to describe a range of HR practices that can facilitate the development of collective gratitude, and discuss as well events that could disrupt the growth of collective empathy. Finally, the authors illustrate the considerable benefits that developing collective gratitude offers both individuals and organizations.

\section{Future Research Directions}

Taken together, the eight articles in this STF suggest thirteen exciting directions for future research, which we list in Table 1 and discus in the following sections. We acknowledge that these might appear to represent a disparate collection of ideas but, like all the articles in this STF, they are nonetheless integrated though a common theme: that emotions derive from the basic biological processes that underlie all human behavior and cognition (Ashkanasy, 2003b). 


\section{Context (social, national, industry)}

In their contribution to this STF, Rothman and Melwani (2017) state an expectation that their model on leader emotional complexity could be extended to future research at the individual, dyadic, group, organizational, and cultural levels. They make the very reasonable suggestion that power differences may influence the effects of leader emotional complexity; and reason that high power differences may reduce leader emotional complexity. When endowed with high levels of power, leaders may focus more on themselves than on others and feel less of a need for emotional complexity. Power differences are one of the key crosscultural differences according to the GLOBE study (House et al., 2004). In this regard, organizations differ considerably in the extent to which they concentrate power in leaders or empower subordinates and teams. Likewise, tolerance for ambiguity or uncertainty is also a major cultural dimension; and this has direct implications for their model. A wide variety of other emotion-related variables may also be influenced by organizational and national differences, so the potential for research on these differences is considerable.

\section{Individual differences (including gender)}

Individual differences are one of the most frequently studied topics in the social sciences, yet more can be done to understand how individual differences may shape the way people respond to affective events. For example, in his article in this STF, Lebel (2017) speculates that there might be differences in how men and women respond to fearful events. The author poses the question as to whether one gender is more likely to seek affiliation and support while the other seeks retaliation. In the same way, it is likely that a wide variety of individual difference variables determine how people respond to various emotional events in organizations. Introverts may respond differently than extroverts to most affective events. Likewise, emotional stability, openness to experiences, agreeableness, and conscientiousness 
may all determine to some extent how people respond not only to fearful events but to the other emotional events portrayed in this special issue.

\section{Complexity (including reciprocal and recursive effects)}

It is often easiest and most straightforward to model unidirectional effects; this is definitely true from a statistical perspective, but also from a theoretical perspective. Yet, as Cropanzano and his colleagues (2017) note in their article in this STF, Affective Events Theory holds that events and emotions operate in a reciprocal manner. The authors acknowledge that their own article focuses on explicating the one-way paths, yet they urge others to explore the complexity of emotional interactions. Likewise, most models of emotional contagion assume that the same emotion communicated by the sender is also the emotion that is experienced by the receiver. Yet emotional displays may elicit a complementary emotion rather than the same emotion. For example although fear is contagious, it is also possible that an observer who witnesses a scared person may respond with compassion rather than fear. Even displays of gratitude may evoke complex responses that vary between people, ranging from mutual gratitude, pride, or even self-deprecation.

\section{Dynamic effects}

For reasons of convenience, most researchers in the social science area tend to examine static effects. Interpersonal behavior is inevitably complex and interactive however, so the behavior of one person determines the response of other interactional partners. In this regard, Oh and Farh (2017), in their contribution to this STF, model how victims' appraisal processes determine their behavioral response to abusive supervision. Yet these authors also note (in their discussion of future research) that dynamic, interactive appraisals need to be explored. For example, how do abusive supervisors respond to subordinates' anger, fear, or sadness? 


\section{Mixed emotions and emotional composition}

In terms of studying discrete emotions, and again out of convenience, most researchers in general prefer to examine simple basic and/or self-conscious emotions such as joy, happiness, fear, anger, pride, and shame. Yet many emotional experiences in life are complex, and involve multiple emotions that are in conflict with each other to some degree. In this regard, Rothman and Melwani (2017) explain how leader emotional complexity can help leaders guide their followers through change efforts. In fact, most organizational change involves a mix of positive and negative outcomes, and leaders' need to display a range of complex emotions to empathize with the mixed emotions experienced by their followers. Their article in this STF provides an excellent example to other researchers about how to model emotional complexity in the workplace.

\section{Multiple levels of analysis}

In addition to studies of individuals, a substantial number of studies look at dyadic interactions, such as between co-workers, romantic partners, service agents and customers, leaders and followers, abusers and victims, etc. (e.g., see Ashkanasy \& Humphrey, 2011a, b). The insightful articles in this STF show however that individually experienced emotions such as gratitude take place in larger organizational contexts. The authors of these articles take a multi-level approach that links the development of experienced emotions to different levels of the organization (e.g., Fehr et al., 2017). Nonetheless, much more could and should be done in this regard, and research at multiple levels is one of the most under-researched areas and as such presents a tremendous opportunity for new research (Ashkanasy \& Humphrey, 2011a,b; Ashkanasy \& Jordan, 2008). For example, Cardon et al. (2017) suggest in their STF article that future research would do well to examine how team entrepreneurial passion influences individual health and well-being, examining both positive and negative consequences. 


\section{New methods (measurement, experimental, physiological, ethnography)}

In many ordinary social interactions, people often feign or hide their emotions (as Jarvis, 2017, demonstrates in his insightful article in this STF). This makes studying emotions in the workplace difficult, especially because people do not always honestly report their emotions. Perhaps even worse, as Jarvis points out, is that people may not even be aware of their true emotions; or of the fact that they are feigning their emotional displays. This dilemma is not unique to research on feigning, since a wide variety of emotions may be hidden, ranging from anger, shame, and even joy. Fortunately, Jarvis outlines a wide variety of research methods that can help us appreciate the true picture. In particular, most studies in the social sciences tend to use self-report scales, and Jarvis has some useful ideas about how to craft these scales. Experimental methods can also be useful to try to determine if subjects become accurately aware of how the experimental conditions might have effected their emotions. Physiological measurements (e.g., heartbeat, blood pressure, sweating, measures of facial movements, etc.) can also provide measures of emotional responses independent of self-reports. Moreover, and as we noted earlier in this introduction, emotions are complex and many emotional episodes of interest to scholars (e.g., responses to crisis situations, job loss, or incidents of bullying) cannot ethically be created in the lab. The complex and intense emotions that arise in these situations might therefore only be amenable to study via ethnography or autoethnography.

A further point is that many of the articles in this STF take a multilevel approach to studying emotions, and this presents a range of issues and opportunities to scholars. In this regard, and as we already noted, emotions are typically studied at the individual level; for example, gratitude is usually thought of as an individual emotion. Yet, as Fehr and his colleagues (2017) observe, we need to develop measures of collective gratitude in order to study this emotion at multiple levels. Likewise, a wide range of other emotions also need 
scales that can be applied to multiple levels of the organizational; as well as to occupational, industry, and societal levels. Fehr and his team suggest that longitudinal methods are particularly useful when examining the emergence of emotions at group and organizational levels.

\section{Positive versus negative emotions}

In general, research has shown that positive emotions are most useful at work most of the time (Judge \& Kammeyer-Muellar, 2008). Nonetheless, we have evolved all of our emotions, even ones such as anger, fear, and shame, because they help us survive under the right circumstances. Knowing the right emotion to portray in a particular circumstance is not always easy, for scholars or for actors in the heat of the moment. People may even have trouble portraying positive emotions, such as gratitude, at the right time and to the right degree. Fortunately, the articles in this STF specify some of the contingencies that stipulate when each of these emotions might be most useful. It is not enough to simply know whether an emotion is positive or negative in affective tone. This is because, as Oh and Farh (2017) demonstrate, anger, fear and sadness are distinct emotional responses to abusive supervision, and therefore are likely to motivate different behavioral reactions.

Also as we noted earlier, emotions are complex, and the interactions among events and emotions and their consequences are even more complex. A good example of this can be found the STF article by Lebel (2017). Lebel models the complex ways in which ostensibly negative emotions like fear can spark positive proactive behavior. Although he focuses on anger and fear, Lebel recommends that future researchers also examine the way positive emotions can stimulate proactive behavior. Overall, it would seem to be clear there is considerable room to examine the interplay between positive and negative emotions and the contingencies that determine when each emotion is most adaptive. 


\section{Climate strength and type}

As Parke and Seo (2017) convincingly argue in their contribution to this STF, affect climate is a crucial aspect of overall organizational climate. These authors lay out a set of key propositions, but also observe there are still many unanswered questions that deserve investigation. Does climate strength change the relationships modelled in their article? How about subcultures? Most organizations are likely to have subcultures or mini-cultures. Do their assumptions hold true for subcultures? How does industry affect climate or national affect climate influence the relationships in their model? Clearly, there is room for considerable research on moderators and mediators.

\section{Linking micro affect and emotions to macro phenomena}

Half of the articles in this STF focus on describing interactions between macro- and micro-level emotion-related phenomena. The authors of these articles do so by theorizing how macro factors - e.g., institution, organization, and group-level mechanisms - might influence and be influenced by patterns of emotion-related behaviors of individuals and teams. The Cardon et al. (2017) STF essay on team entrepreneurial passion, for example, introduces a rich variety of group-based mechanisms including similarity-attraction, shared group identity, group diversity and variance, and bottom-up emergence of collective processes.

Moving to the organizational level, Parke and Seo (2017) propose a model of the antecedents and effects of an organization's affective climate, which influence how employees experience and express their emotions, which in turn impacts various units' outcomes. Antecedents of affective climate include mechanisms such as company practices and leaders' actions. This work represents an extension of prior research that suggests how emotion-related organizational routines (called "emotional capability") could facilitate radical change (e.g., Huy, 1999; 2002). It thus shows how these mechanisms underlie the 
relationships between diverse types of collective emotions in the context of organizational continuity and evolutionary change.

Likewise, the Fehr et al. (2017) multilevel model of gratitude draws upon mechanisms such as shared interactions and emergent processes that characterize an organizational culture. These authors' focus on how HR practices facilitate the development of collective gratitude to garner organizational benefits shows how a healthy affective climate can be built. This work again shows how organization-level theorizing - through the mechanisms of emotion-based HR practices and routines - can shape the affective dimension of organizational culture.

Moving to the institutional level, Jarvis (2017) describes how institution-level beliefs shape feigned emotional displays. This work shows how interactions among various mechanisms - including individual-level emotion regulation and (feigned) emotion display behaviors, group-level socialization, and institution-level logics (i.e., the patterns of cultural symbols and practices, values and beliefs by which people organize and provide meaning to their daily activity) - can be employed to explain how people can maintain or change an institutional order.

Nonetheless, there is still insufficient research that theorizes how individual-level or group-level emotions influence and are influenced by organization-level and institution-level outcomes. For example, only a handful of field studies have shown how unexpected grouplevel emotions from the lower level of the organization might influence the entire governance of organizations - and even cause decline in organizational performance (e.g., see Huy, 2011; Huy, Corley, \& Kraatz, 2014; Vuori \& Huy, 2016). Although Huy and his colleagues have studied the linkages between micro-emotions and macro-organizational effects in the context of strategic change, these micro-to-macro linkages might also apply to other themes of interest to organization and strategy scholars. Illustrative themes might include social 
movements, changes in institutional logics, mergers and acquisitions, strategic alliances, or bottom-up organizational innovation.

One frequent cause of failed theorizing attempts relates to oversimplification of the organizational context. Organization scholars generally construe an organization as a coalition of diverse groups with diverse preferences and interests (Cyert \& March, 1963/2013), yet many theorizing attempts construe organizations as simple psychological reflections of an individual. This implies that findings from research in psychology can be mechanically applied to an organization acting in effect as a single person; and reviewers typically do not accept such an oversimplification. This is a well-known issue in theorizing called the "aggregation problem" (Powell, Lovallo, \& Fox, 2011). Instead, micro-macro scaling mechanisms should start from a more nuanced understanding of the organization as a plurality of diverse groups (and individuals), and study how interactions among these groups (including affect-based interactions) influence the quality of inter-group and grouporganization interactions. They might also study how the aggregation of diverse groups interactions influences organization-level outcomes and vice versa. In this regard, beyond the mechanisms proposed by the articles in this STF, Huy (2012) and Vuori and Huy (2016) propose emotion-based scaling mechanisms that could help foster future research into the micro-macro links. Illustrative mechanisms include group focus emotions that are linked to social identity; collective emotions; emotion-based routines; and organizational structures.

\section{Group-focused emotions and social identity}

Appraisal theories of emotion (Ellsworth \& Scherer, 2003; Smith \& Ellsworth, 1985) view emotions as arising when a person appraises an event as harming or helping her or his important personal goals or well-being. But people can also experience strong emotions when events do not directly affect themselves and those who are personally close to them. People can also experience what scholars call group-focus or group-level emotions when, for 
example, they are joyful when their sports team wins (Smith, Seger, \& Mackie, 2007). In this regard, scholars have shown that group-focus emotions predict collective behavior more strongly than other individual emotions do. Group-focused emotions could also be linked to social identity (Huy, 2011). In this case, organization members who identify strongly with their group (or firm) can be expected to experience emotions that are similar to those of others in the organization when faced with events that impact their collective's identity or welfare.

\section{Collective emotions}

Two of the articles in this STF (Cardon et al., 2017; Fehr et al., 2017) address collective emotions, which represent the composition of various shared emotions of a group's members (Barsade \& Gibson, 1998) and have been shown to influence a variety of group outcomes (van Zomeren, Spears, \& Fischer, 2004). Collective emotions do not just reflect an emotionally homogenous group but can also consist of sizable proportions of different shared emotions; for example, seventy percent of members experiencing negative emotions while the other thirty percent experience positive emotions. Since a strategic change is unlikely to affect all work units in the same organization in the same way, the composition of collective emotions might be heterogeneous in large organizations inhabited by groups with distinctive roles, values, and interests (Sanchez-Burks \& Huy, 2009).

\section{Some Additional Thoughts and Future Research Directions}

In addition to the foregoing directions for future research - that emerge directly from the articles published in this STF - we list in Table 1 five additional topics that, although not explicitly addressed in the articles, are inspired by them. We discuss these topics next. 


\section{Emotion-Based Organizational Routines}

Individual emotions can become collective and organizational through the enactment of what is called organizational emotional capability, which refers to the organizational ability to recognize, to monitor, to discriminate, and to attend to emotions of employees at both the individual and the collective levels (Huy, 1999, 2005). This ability is built into the organization's routines, which reflect the collective knowledge and skills to manage the emotions of its members - when needed to realize organizational outcomes.

In the context of strategic change, Huy $(1999,2005)$ described various emotion management routines (also called emotional dynamics) that constitute an organization's emotional capability such as emotional experiencing, reconciliation, and encouragement; and which express or elicit specific positive emotions during strategic change - such as empathy, sympathy, and hope - to foster various change processes. Although alluded to in the STF articles, the extent to which these emotional dynamics are relevant to interfirm emotion management and their associated boundary conditions in other interfirm contexts has not received enough empirical investigation and more nuanced theorizing.

\section{Organizational structures}

Also alluded to, but not directly addressed in the articles, are differences in emotional experiences among organizational groups that might arise because of the influence of their varied positions in the organizational structure. If groups specialize in different tasks and focus on different matters, they likely perceive things differently and regard some matters as more important than others. Differing emotions among groups could arise because of the structural distribution of attention (Ocasio, 1997). To illustrate, the extent to which strategic change evokes threats to some managers' status and power within the structure of the organization can trigger strong emotions (Vuori \& Huy, 2016). The organizational hierarchy grants unequal formal status on various organization members and groups through titles and 
responsibilities. This status determines in part an individual's "power" (i.e., the extent of their control over resources that other members value, see Pfeffer, 1981). Organization members who value status and power likely compete with one another to obtain or maintain their status and may feel strong emotions if they perceive related threats. Low-status employees likely fear higher status individuals (Menges \& Kilduff, 2015).

\section{Emotion Management Actions}

Several of the STF articles touch upon issues of emotion management (e.g., Jarvis, 2017; Lebel, 2017; Oh \& Fahr, 2017), but only tangentially. Nonetheless, a good deal of literature has focused on this topic, especially in the form of individual leader interpersonal emotion management (e.g., Humphrey, Pollack, \& Hawver, 2008; Kaplan, Cortina, Ruark, LaPort, \& Nicolaides, 2014). There has been much less examination however as to how emotion management actions influence organization-level outcomes (e.g., organizational continuity and change which we elaborate below) or are embedded in organization-level constructs (such as organizational routines). Within this topic, we identify two particular lines of potential future research: (a) Organizational-level paradoxes involving affect such as emotional balancing continuity and change and (b) emotion-related organizational routines.

\section{Organizational-level paradoxes involving affect}

Huy $(2002,2005)$ research illustrates the usefulness of investigating organizationlevel paradoxes involving affect (Smith \& Lewis, 2011). Huy (2002), for instance, has drawn attention to the importance of managing emotions related to both organizational continuity and change, rather than focusing on change alone. Emotional balancing is necessary because too much and too rapid change risks generating chaos, while too little and too slow change risks creating inertia. Emotional balancing at the organization level involves some organizational groups displaying high emotional commitment to pursue change projects with other groups attending to the emotions of change recipients to maintain operational continuity 
(as a type of organizational paradox). Future research can investigate emotion-related processes and mechanisms that are involved in organizations pursuing various tensions, such as efficiency versus innovation, short versus long term benefits, economic versus social welfare.

Emotion-related organizational routines. Beyond interpersonal leader emotion management actions, emotion management can also be performed thanks to embedded organizational action routines that attend to recipient employees' emotions caused by major change (e.g., Huy, 1999). Future research in micro-macro linkages would thus do well to explore the various types of organization-level paradoxes and emotion management actions that are relevant for diverse organizational and institutional contexts; and how this organization-level emotional capability could be developed. Affective differences in contexts could matter for organizational performance (e.g., Huy, 2002; Vuori \& Huy, 2016). For example, organizations that tend not to value emotional sensitivity, such as some financial trading companies, may have less emotional resilience and adaptive capacity during disruptive change than organizations that value it more, such as human care organizations (Barsade \& O’Neill, 2014).

\section{Emotional Labor}

As we noted earlier, while emotional labor has been a major topic of research ever since publication of Hochschild's (1983) seminal book on the topic, the last few years have seen an impressive amount of work on the topic (as documented by Grandey, Diefendorff, and Rupp, 2013). Emotional labor takes place whenever people modify their emotional displays in order to meet organizational display rules that specify the emotions they should be expressing. For example, restaurants and retail establishments often urge their employees to provide "service with a smile". Although (as we noted earlier) the articles in this STF brush on issues related to emotion management, none address this topic directly. Nonetheless, and 
despite the considerable amount of work that has been done on this topic, there are still major avenues of research on this topic that need exploring.

In particular, the "bright side" of emotional labor offers fruitful prospects. The predominant views of emotional labor stem from Hochschild's (1983) perspective that performing emotional labor can be stressful and can lead to feelings of inauthenticity. This leads to an investigation of emotional labor in companies and in occupations known to have high levels of employee dissatisfaction; as well as a focus on negative outcomes such as stress and burnout. As a result, the positive aspects of emotional labor have largely been overlooked and under-investigated.

Humphrey, Ashforth, and Diefendorff (2015) argue in this regard that the concentrated focus on the undesirable aspects of emotional labor has caused researchers to overlook the many positive aspects of emotional labor. In their review of existing research, they concluded that the deleterious effects of emotional labor occurred primarily when people used the wrong form of emotional labor, surface acting, instead of the more beneficial forms, deep acting and natural, spontaneous and genuine emotions (Ashforth \& Humphrey, 1993). Humphrey and his co-authors (2015) further maintain that the use of surface acting is often caused by poor person-job fit, and that emotional labor is beneficial for those with good job fit, especially extroverts and people with high emotional stability, high emotional intelligence, and high positive trait affect. Thus, similar to the approach adopted by Lebel (2017), we argue that, instead of searching for negative effects in companies known for mistreating their employees, future research should examine exemplary workers in companies known for providing outstanding customer service and for having high employee job satisfaction.

There has also been some very exciting research extending emotional labor beyond the service context. Researchers have been applying emotional labor concepts to leadership 
and to interactions among co-workers (Ashkanasy \& Humphrey, 2011b; Fisk \& Friesen, 2012; Gardner, Fischer, \& Hunt, 2009; Humphrey et al. 2008; Iszatt-White, 2009; 2013). Emotional labor may be particularly relevant to leadership because "Leaders use emotional labor to regulate their own emotions and to manage the moods, job attitudes, and performance of their followers" (Humphrey, 2012: 740). Leaders and subordinates may use surface acting, deep acting, or genuine emotions when interacting with each other and the choice of emotional labor strategy may have a profound effect on the quality of their relationships. The potential to do research in this area is enormous.

\section{Emotional Intelligence}

Finally, we note that emotional intelligence, which is an individual difference variable, and continues to be one of the most researched topics in the area of emotions and management, is not addressed directly in any of the STF articles. Nonetheless, emotionrelated individual differences still underpin much of the work on emotion in organizational settings, especially at the more micro-levels of analysis (e.g., see Cropanzano et al., 2017; Lebel, 2017; Oh \& Farh, 2017). In this regard, Ashkanasy and Daus (2005) brought clarity to this booming field by categorizing the different streams of emotional intelligence research into ability measures, self-reports based on the Mayer-Salovey (1997) model, and mixed competency models of emotional intelligence. Irrespective of which stream, all measures of emotional intelligence deal with the individual's ability to regulate and to perceive emotions, both with regard to self and others and, as such, are implied in most theories of emotion.

Despite ongoing controversy (Antonakis, Ashkanasy, \& Dasborough 2009), emotional intelligence measures have shown a wide range of utility across the spectrum of work-related outcomes. In this regard, two recent meta-analyses found that emotional intelligence was positively related to physical, mental, and psychosomatic health (Martins, Ramalho, \& Morin, 2010; Schutte, Malouff, Thorsteinsson, Bhullar, \& Rooke, 2007). It is 
likely that this greater health contributes to performance and well-being at work. Walter, Cole, and Humphrey's (2011) review found that emotional intelligence is positively related to leadership emergence, the performance of effective leadership behaviors, and overall leadership effectiveness. More recently, Miao, Humphrey, and Qian (2016) also found in a meta-analysis that leaders high on emotional intelligence have subordinates with higher job satisfaction; moreover, the results of this study show that emotional intelligence demonstrates incremental validity and relative importance (controlling for Big Five personality and cognitive ability). Other Meta-analysis findings (O’Boyle, Humphrey, Pollack, Hawver, \& Story, 2011) also tell us that emotional intelligence predicts job performance, even when controlling for personality and cognitive ability. Given these important findings, future research clearly needs to continue, particularly to understand how emotional intelligence relates to multiple levels of analysis, on boundary conditions, on training and development, and on many other issues. Given the considerable incremental validity that emotional intelligence measures have shown across a wide domain of work-related behaviors, it should now be expected that researchers routinely include measures of emotional intelligence in their studies. Thus, we argue that, although emotional intelligence was not addressed in the articles included in this STF, it remains an important topic that can be benefit from deeper and more rigorous research.

\section{Conclusion}

The study of emotions and affect in organizational settings has come a long way in the last two decades with the seminal call for action by Ashforth and Humphrey (1995). Nonetheless, while we scholars of emotion and affect in organizations no longer need to introduce our articles by bemoaning the lack of research in this regard (e.g., see Fisher \& Ashkanasy, 2000), the research outlined in this STF tell us that there remains tremendous 
scope to further our understanding in this field. Especially exciting are emerging fields such as the roles of context and individual differences (including gender) also including real-world complexity such as dynamic effects, mixed emotions, emotional composition, emotion management, emotion-related organizational routines, and interactions between macro and micro-level factors. Multi-level issues and new methods are also opening up new avenues for research and theory. Moreover, and as we noted earlier, there still remains much additional scope for development in established fields such as emotional labor and emotional intelligence. Our hope is that this STF will stimulate further development in this field and we eagerly look forward to seeing what comes next.

\section{References}

Antonakis, J., Ashkanasy, N. M., \& Dasborough, M. T. 2009. Does leadership need emotional intelligence? The Leadership Quarterly, 20: 247-261.

Ashforth, B. E., \& Humphrey, R. H. 1993. Emotional labor in service roles: The influence of identity. Academy of Management Review, 18: 88-115.

Ashforth, B. E., \& Humphrey, R. H. 1995. Emotion in the workplace: A reappraisal. Human Relations, 48: 97-125.

Ashkanasy, N. M. 2003a. Emotions in organizations: A multilevel perspective. In F. Dansereau and F. J. Yammarino (Eds.), Research in multi-level issues, Vol. 2: 9-54. Oxford, UK: Elsevier Science.

Ashkanasy, N. M. 2003b. Emotions at multiple levels: An integration. In F. Dansereau and F. J. Yammarino (Eds.), Research in multi-level issues, Vol. 2: 71-81. Oxford, UK: Elsevier Science.

Ashkanasy, N. M. 2004. Emotion and performance. Human Performance, 17: 137-144. 
Ashkanasy, N. M., \& Daus, C. S. 2005. Rumors of the death of emotional intelligence in organizational behavior are vastly exaggerated. Journal of Organizational Behavior, 26: 441-452.

Ashkanasy, N. M., \& Härtel, C. E. J. 2014. Positive and negative affective climate and culture: The good, the bad, and the ugly. In B. Schneider \& K. Barbera (Eds.), The Oxford handbook of organizational culture and climate: 136-152. New York: Oxford University Press.

Ashkanasy, N. M., \& Humphrey, R. H. 2011a. Current emotion research in organizational behavior. Emotion Review, 3: 214-224.

Ashkanasy, N. M., \& Humphrey, R. H. 2011b. A multi-level view of leadership and emotions: Leading with emotional labor. In A. Bryman, D. Collinson, K. Grint, B. Jackson, \& M. Uhl-Bien (Eds.), Sage handbook of leadership: 363-377. London, UK: Sage.

Ashkanasy, N. M. \& Jordan, P. J. 2008. A multilevel view of leadership and emotion. In R.H. Humphrey (ed.), Affect and emotion: New directions in management theory and research: 17-39. Charlotte, NC: Information Age Publishing.

Ashton-James, C. E., \& Ashkanasy, N. M. 2008. Affective events theory: A strategic perspective. In W. J. Zerbe, C. E. J. Härtel, \& N. M. Ashkanasy (Eds.), Research on emotion in organizations, vol. 4: 1-34. Bingley, UK: Emerald Group Publishing.

Barsade, S. G., \& Gibson, D. E. 1998. Group emotion: A view from top and bottom. In M. A. Neale, \& E. A. Mannix (Eds.), Research on managing groups and teams, Vol. 1: 81102. Stamford, CT: JAI Press.

Barsade, S. G., \& O’Neill, O. A. 2014. What's love got to do with it? A longitudinal study of the culture of compassionate love and employee and client outcomes in the long-term care setting. Administrative Science Quarterly, 59: 551-598. 
Cardon, M. S., Foo, M., Shepherd, D., \& Wiklund, J. 2012. Exploring the heart:

Entrepreneurial emotion is a hot topic. Entrepreneurship Theory and Practice, 36: 110.

Cardon, M., Post, C., \& Forster, W. (2017). Team entrepreneurial passion (TEP): Its emergence and influence in new venture teams. Academy of Management Review, 42: $\mathrm{XXX}-\mathrm{XXX}$.

Cardon, M. S., Wincent, J., Singh, J., \& Drnovsek, M. 2009. The nature and experience of entrepreneurial passion. Academy of Management Review, 34: 511-532.

Cropanzano, R., Dasborough, M., \& Weiss, H. (2017). Affective events and the development of leader-member exchange. Academy of Management Review, 42: XXX-XXX.

Cyert, R. M., \& March, J. G. 2013. A behavioral theory of the firm. Eastford, CT: Martin Fine Books (First published in 1963 by Prentics-Hall).

de Rivera, J. 1992. Emotional climate: Social structure and emotional dynamics. In K. T. Strongman (Ed.), International review of studies on emotions, vol. 2: 197-218. New York: Wiley.

Dutton, J. E., \& Quinn, R. E. 2003. Positive organizational scholarship: Foundations of a new discipline. San Francisco: Berrett-Koehler Publishers.

Elfenbein, H. A. 2007. Emotion in organizations: A review and theoretical integration. The Academy of Management Annals, 1: 315-386.

Ellsworth, P. C., \& Scherer, K. G. 2003. Appraisal processes in emotion. In R. J. Davidson, H. Goldsmith, \& K. G. Scherer (Eds.), Handbook of affective sciences, vol. 29: 572595. New York: Oxford University Press.

Emmons, R. A., \& McCullough, M. E. (Eds.). 2004. The psychology of gratitude. New York: Oxford University Press. 
Fehr, R., Fulmer, A., Awtrey, E., \& Miller, J. (2017). The Grateful Workplace: A Multilevel Model of Gratitude in Organizations. Academy of Management Review, 42: XXXXXX.

Fisher, C.D. \& Ashkanasy, N. M. 2000. The emerging role of emotions in working life: An introduction. Journal of Organizational Behavior, 21: 123-129.

Fisk, G. M., \& Friesen, J. P. 2012. Perceptions of leader emotion regulation and LMX as predictors of followers' job satisfaction and organizational citizenship behaviors. The Leadership Quarterly, 23: 1-12.

Fox, S., \& Spector, P. E. 2002. Emotions in the workplace: The neglected side of organizational life introduction. Human Resource Management Review, 12: 167-171.

Fredrickson, B. L. 2001. The role of positive emotions in positive psychology: The broadenand-build theory of positive emotions. American psychologist, 56: 218-226.

Gardner, W.L., Fischer, D., \& Hunt, J.G. 2009. Emotional labor and leadership: A threat to authenticity? The Leadership Quarterly, 20, 466-482.

Goleman, D. 1995. Emotional Intelligence: Why it can matter more than IQ. New York: Bantam Books.

Goleman, D. 1998. Working with emotional intelligence. New York: Bantam.

Grandey, A. A., Diefendorff, J. M., \& Rupp, D. E. (Eds.) 2013. Emotional labor in the 21st century: Diverse perspectives on emotion regulation at work. New York: Routledge.

Hodgkinson, G. P, \& Healey, M. P. 2011. Psychological foundations of dynamic capabilities: Reflexion and reflection in strategic management. Strategic Management Journal, 32: $1500-1516$.

Hochschild, A. R. 1983. The managed heart: Commercialization of human feeling. Berkeley, CA: University of California Press. 
House, R. J., Hanges, P. J., Javidan, M., Dorfman, P. W., \& Gupta, V., \& GLOBE Associates. 2004. Leadership, culture and organizations: The GLOBE study of 62 societies. Thousand Oaks, CA: Sage Publications, Inc.

Humphrey, R. H. 2002. The many faces of emotional leadership. The Leadership Quarterly, 13: 493-504.

Humphrey, R. H. 2012. How do leaders use emotional labor? Journal of Organizational Behavior, 33: 740-744.

Humphrey, R. H. 2013. Effective leadership: Theories, cases, and applications. Los Angeles, CA: Sage.

Humphrey, R. H., Ashforth, B. E., \& Diefendorff, J. 2015. The bright side of emotional labor. Journal of Organizational Behavior, 36: 749-769.

Humphrey, R. H., Pollack, J. M., \& Hawver, T. 2008. Leading with emotional labor. Journal of Managerial Psychology, 23: 151-168.

Hunt, J.G., Gardner, W.L., \& Fischer, D. 2008. Leader emotional displays from near and far: The implications of close versus distant leadership for leader emotional labor and authenticity. In R. H. Humphrey (Ed.), Affect and emotion: New directions in management theory and research: 43-65. Charlotte, NC: Information Age Publishing.

Huy, Q. N. 1999. Emotional capability, emotional intelligence, and radical change. Academy of Management Review, 24: 325-345.

Huy Q. N. 2002. Emotional balancing of organizational continuity and radical change: the contribution of middle managers. Administrative Science Quarterly, 47: 31-69. 
Huy, Q. N. 2005. An emotion-based view of strategic renewal. In G. Szulanski, J. Porac, \& Y. Doz (Eds.), Strategy Process: Advances in Strategic Management: 3-37. New York: Elsevier Science.

Huy, Q. N. 2011. How middle managers' group-focus emotions and social identities influence strategy implementation. Strategic Management Journal, 32: 1387-1410.

Huy, Q. N. 2012. Emotions and strategic organization: Opportunities for impactful research. Strategic Organization, 10: 240-247.

Huy, Q. N., Corley, K., \& Kraatz, M. S. 2014. From support to mutiny: Shifting legitimacy judgments and emotional reactions impacting the implementation of radical change. Academy of Management Journal, 57: 1650-1680.

Iszatt-White, M. 2009. Leadership as emotional labour: The effortful accomplishment of valuing practices. Leadership, 5: 447-467.

Iszatt-White, M. 2013. Leadership as emotional labor: So what's new? In M. Iszatt-White (Ed.), Leadership as Emotional Labor: 14-36. London, UK: Routledge.

Jarvis, L. (2017). Feigned versus Felt: Feigning Behaviors and the Dynamics of Institutional Logics. Academy of Management Review, 42: XXX-XXX.

Judge, T.A. \& Kammeyer-Muellar, J.D. 2008. Affect, satisfaction, and performance. In N. M. Ashkanasy \& C. L. Cooper (Eds.), Research Companion to Emotion in Organizations: 136-151). Cheltenham, UK: Edward Elgar Publishing Limited.

Kaplan, S., Cortina, J., Ruark, G., LaPort, K., \& Nicolaides, V. 2014. The role of organizational leaders in employee emotion management: A theoretical model. The Leadership Quarterly, 25: 563-580.

Powell, T. Lovallo, D. \& Fox, C.. 2011. Behavioral strategy. Strategic Management Journal, 32:1369-1386 .

Lazarus, R. S., \& Folkman, S. 1984. Stress, appraisal, and coping. New York: Springer. 
Lebel, R.D. 2017. Moving beyond fight and flight: A contingent model of how anger and fear spark productivity. Academy of Management Review, 42: XXX-XXX.

Luthans, F. 2002. The need for and meaning of positive organizational behavior. Journal of Organizational Behavior, 23: 695-706.

Martins, A., Ramalho, N. \& Morin, E. 2010. A comprehensive meta-analysis of the relationship between Emotional Intelligence and health. Personality and Individual Differences, 49: 554-564.

Mayer, J. D., \& Salovey, P. 1997. What is emotional intelligence? In P. Salovey \& D. J. Sluyter (Eds.), Emotional development and emotional intelligence: Educational implications: 3-25. New York: Basic Books.

Menges, J. \& Kilduff, M. 2015. Group Emotions: Cutting the Gordian Knots Concerning Terms, Levels of Analysis, and Processes. The Academy of Management Annals, 9: 845-928.

Miao, C., Humphrey, R. H., \& Qian, S. 2016. Leader emotional intelligence and subordinate job satisfaction: a meta-analysis of main, mediator, and moderator effects. Personality and Individual Differences, 102: 13-24.

O’Boyle, E. H., Humphrey, R. H., Pollack, J. M., Hawver, T. H., \& Story, P. A. 2011. The relation between emotional intelligence and job performance: A meta-analysis. Journal of Organizational Behavior, 32: 788-818.

Oh, K. J., \& Farh, C. (2017). An emotional process theory of how subordinates appraise, experience, and respond to abusive supervision over time. Academy of Management Review, 42: XXX-XXX.

Ocasio, W. 1997. Towards an attention-based view of the firm. Strategic Management Journal, 18: 187-206. 
Ostroff, C., Kinicki, A. J., \& Muhammad, R. S. 2013. Organizational culture and climate. In I. B. Weiner, N. W. Schmitt, \& S. Highhouse (Eds.), Handbook of psychology, volume 12: Industrial and organizational psychology (2nd ed.): 643-676. New York: Wiley. Parke, M., \& Seo, M-G. (2017). The role of affect climate in organizational effectiveness. Academy of Management Review, 42: XXX-XXX.

Parker, S. K., Bindl, U. K., \& Strauss, K. 2010. Making things happen: A model of proactive motivation. Journal of Management, 36: 827-856.

Pfeffer, J. 1981. Power in organizations. Marshfield, MA: Pitman Publishing.

Rothman, N., \& Melwani, S. (2017). Feeling mixed, ambivalent and in flux: The social functions of emotional complexity for leaders. Academy of Management Review, 42: XXX-XXX.

Sanchez-Burks, J., \& Huy, Q. N. 2009. Emotional aperture and strategic change: The accurate recognition of collective emotions. Organization Science, 20: 22-34.

Schneider, B., Ehrhart, M. G., \& Macey, W. H. 2013. Organizational climate and culture. Review of Psychology, 64: 361-388.

Schutte, N. S., Malouff, J. M., Thorsteinsson, E. B., Bhullar, N., \& Rooke, S. E. 2007. A meta-analytic investigation of the relationship between emotional intelligence and health. Personality and Individual Differences, 42: 921-933.

Seo, M., Taylor, M. S., Hill, N. S., Zhang, X., Tesluk, P. E., \& Lorinkova, N. M. 2012. The role of affect and leadership during organizational change. Personnel Psychology, 65: 121-165.

Shepherd DA, Wiklund J, Haynie J.M. 2009. Moving forward: Balancing the financial and emotional costs of business failure. Journal of Business Venturing 24: 134-148.

Smith, C. A., \& Ellsworth, P. C. 1985. Patterns of cognitive appraisal in emotion. Journal of Personality and Social Psychology, 48: 813-838. 
Smith, W. K., \& Lewis, M. W. 2011. Toward a Theory of Paradox: A Dynamic equilibrium Model of Organizing. Academy of Management Review, 36(2): 381-403.

Smith, E. R., Seger, C. R., \& Mackie, D. A. 2007. Can emotions be truly group level? Evidence regarding four conceptual criteria. Journal of Personality and Social Psychology, 93: 431-446.

To, M. L., Fisher, C. D., \& Ashkanasy, N. M. 2015. Unleashing angst: Negative mood, learning goal orientation, psychological empowerment, and creative behaviour. Human Relations, 68: 1601-1622.

To, M. L., Fisher, C. D., Ashkanasy, N. M., \& Rowe, P. A. 2012. Within-person relationships between mood and creativity. Journal of Applied Psychology, 97: 519-612.

van Zomeren, M., Spears, R., \& Fischer, A. H. 2004. Put your money where your mouth is! Explaining collective action tendencies through group-based anger and group efficacy. Journal of Personality and Social Psychology, 87: 649-664.

Vuori, T. O. and Q. N. Huy 2016. Distributed attention and shared emotions in the innovation process: How Nokia lost the smartphone battle. Administrative Science Quarterly, 61: $9-51$.

Waldman, D. A., Balthazard, P. A., \& Peterson, S. 2011. Social cognitive neuroscience and leadership. The Leadership Quarterly, 22: 1092-1106.

Walter, F, Cole, M. S., \& Humphrey, R. H. 2011. Emotional intelligence: Sine qua non of leadership or folderol? Academy of Management Perspectives, 25(1):.45-59.

Weiss H. M., \& Cropanzano R. 1996. Affective Events Theory: A theoretical discussion of the structure, causes and consequences of affective experiences at work. In B. M. Staw \& L. L. Cummings (Eds.), Research in organizational behavior, vol. 18: 1-74. Greenwich, CT: JAI Press. 


\section{Author bios}

Neal M. Ashkanasy is Professor of Management in the UQ Business School, The University of Queensland. He studies emotion in organizations, leadership, culture, and ethical behavior. He has published in journals such as the Academy of Management Journal and Review and the Journal of Applied Psychology. He served as Editor-in-Chief of the Journal of Organizational Behavior, Associate Editor for the Academy of Management Review, and is currently series editor for Research on Emotion in Organizations.

Ronald H. Humphrey is a Distinguished Professor of Leadership at Lancaster University, U.K., and Director of the Centre for Leadership Studies and Practice. He published a textbook: Effective Leadership: Theories, Cases, and Applications (Sage, 2013). He is currently studying how empathic, emotionally intelligent leadership contributes to leadership emergence, leadership performance, follower performance, job satisfaction (for both the leader and follower), and organizational citizenship behavior. He also studies emotional labor, identity theory, and other topics.

Quy Nguyen Huy is professor of strategic management at INSEAD. His research focuses on the social emotional dimensions of strategic processes including strategic change, innovation, and entrepreneurship. His research has won multiple awards from the Academy of Management and was published in prestigious academic and practitioner journals including the Administrative Science Quarterly, the Academy of Management Review, the Academy of Management Journal, Organization Science, Strategic Management Journal, Harvard Business Review, and MIT Sloan Management Review. 
Table 1. Seventeen Future Research Directions

Ideas that derive directly from the articles in this STF

- The importance of context

- Individual differences and gender

- Complexity

- Dynamic effects

- Mixed emotions and emotional composition

- Multiple levels of analysis

- New methods

- Positive versus negative emotions

- Climate strength and type

- Linking micro-level affect and emotions to macro-level phenomena

- Group-focus emotions and social identity

- Collective emotions.

Additional ideas inspired by the articles in this STF

- Emotion-based organizational routines

- Organizational structures

- Emotion management actions

- Emotional labor

- Emotional intelligence 